\title{
Encrucijadas teóricas en la sociología del siglo XX
}

\author{
Ángeles Lizón \\ Universitat Autònoma de Barcelona. Departament de Sociologia \\ angeles.lizon@uab.cat
}

Recibido: 23-03-2009

Aceptado: 25-01-2010

\section{Resumen}

Con la idea de entresacar los nudos analíticos más interesantes de las principales controversias teóricas en la sociología del XX, a continuación se propone un recorrido sinóptico por aquella porción de la disciplina que ha retenido algún tipo de pulsión analítica. Para hacerlo, se utilizarán las categorías básicas de causas estructurales y razones epistémicas, señalando su predominio, exclusión o posposición en cada caso. Por causas (cognitivas y sociológicas) se hará aquí referencia a aquellas estructuras capaces de determinar dominios de competencia a los microestados (simbólicos, preferenciales u otros). Por razones epistémicas (objetivas o racionales) se entenderán razones lógicas o epistemológicas capaces de dar lateralmente cuenta de efectos macrosociales. Estas categorías parecen particularmente útiles para disolver las discrepancias en distinciones que permitan identificar mejor las diferentes posiciones en juego, a la vez que adecuadas para parafrasear algunas críticas en términos ajustados al horizonte paradigmático en el que tendrá que moverse la disciplina a comienzos del nuevo milenio.

Palabras clave: causas sociológicas, causas cognitivas, razones epistémicas, funcionalismo estructural, construccionismo social, universales humanos, estructuralismo conductista, estructuralismo lingüístico, estructuralismo genético, modelo económico estándar, modelo económico de racionalidad limitada, psicología folk, psicología conductista, psicología cognitiva, psicología evolucionaria.

\section{Abstract. Theoretical Crossroads in Twentieth Century Sociology}

With the idea of reviewing the most interesting sociological debates along the past century, this paper will present a brief synopsis of those contributions that seemed to retain a clearer theoretical drive. Basic categories of causes and reasons will be used here to shed some light on central questions, and dissolve the main differences into some core analytical features. For cognitive and sociological causes we refer here to objective social and cognitive structures enabled to determine dominions of competence to certain microstates 
(symbolic or other). In a similar way, for epistemic reasons one should understand those objective or rational reasons qualified to give account of lateral macro social effects. These categories have proved to be useful, not only for dealing with the various positions visited, but especially adequate for opposing some critical views in terms closely related to the new paradigmatic horizon social sciences will face in this millennium.

Key words: social causes, cognitive cuases, epistemic reasons, functional structuralism, social constructionism, human universals, linguistic perspective, genetic perspective, evolutionary perspective, standard model of rationality, bounded model of rationality, folk psychology, conductism psychology, cognitive psychology, evolutionary psychology.

\section{Sumario}

1. Supremacía indiscriminada de las causas sociológicas

2. Universales humanos y causas cognitivas: El intercambio mente-medio

3. Prevalencia analítica de las razones epistémicas
4. ¿Una matriz integradora para las ciencias del comportamiento?

Epílogo

Referencias bibliográficas

Alimentados por distintas ideas respecto de lo que ha de tomarse por buena ciencia social, la mayor parte de las grandes disputas teóricas en las ciencias sociales han respondido a fuertes compromisos con concepciones dispares acerca de la naturaleza de los antecedentes explicativos y de los factores comprometidos en la explicación del comportamiento humano y social. Aun admitiendo que todas esas controversias atañen al conjunto de las disciplinas del área, la idea de recuperarlas desde la sociología tiene la intención de poner de manifiesto las consecuencias adversas de un excesivo celo por preservar la autonomía disciplinaria. Así, atendiendo a las categorías básicas de causas estructurales y razones epistémicas, a continuación se reconstruirá el núcleo de las principales encrucijadas teóricas en la sociología del siglo XX, haciendo hincapié en el interés analítico de esta distinción y señalando en cada caso el efecto inmediato de su inclusión, exclusión, irresolución o incorrecta combinación.

En términos generales, por causas estructurales se hará referencia a estructuras objetivas capaces de determinar microestados o estados subjetivos (creencias, deseos o preferencias, capacidades perceptivas, simbólicas u otras). De modo específico, se harán coincidir las causas cognitivas con aquellas disposiciones o habilidades endógenas que capacitan para dar respuestas familiares o espontáneas que sirven para prefigurar marcos recurrentes de acción e interacción humanas. Se trata de disposiciones o capacidades no conscientes y básicamente innatas que proporcionan salidas adaptadas a condiciones habituales o entornos estables y que requieren del concurso de insumos sociales o culturales para activarse o alcanzar su pleno desarrollo. Si bien hoy se trabaja sobre un amplio repertorio de capacidades evolucionadas (Gigerenzer y Selten [eds.], 
2002), quizá la más estudiada haya sido el lenguaje, una estructura cognitiva universal tempranamente recogida por el estructuralismo lingüístico y sistematizada por la psicolingüística de Noam Chomsky que precedió a la investigación multidisciplinaria de la mente en las ciencias cognitivas modernas. Es precisamente evocando esa idea de una arquitectura cognitiva de la mente y sus capacidades y recursos evolucionados que se opta por designarlas con tal nombre.

Por causas sociológicas, en cambio, se hará referencia explícita a aquellas estructuras exógenas (roles, normas e instituciones) capaces de moldear las preferencias individuales y domeñar los comportamientos colectivos en función de valores sistémicos o grupales impuestos. Si bien pueden retrotraerse al plano consciente, también suelen operar a sus espaldas, economizando en costes de decisión y restringiendo las posibilidades de acción y decisión autónoma. Tradicionalmente recuperadas por el estructuralismo de los hechos sociales, su primacía, evidente ya en la sociología fundacional francesa, es consolidada por el funcionalismo estructural de la primera mitad del siglo XX.

En lo que a las razones hace referencia, se atenderá centralmente a la preocupación de la epistemología por articular una teoría normativa de la formación de creencias capaz de indicar qué se ha de creer racionalmente y qué creencias están efectivamente justificadas. Aunque existen desacuerdos entre las distintas versiones, e incluso se admiten atajos intuitivos que amplían considerablemente la noción de intencionalidad racional, la imagen estándar de lo que se entiende por razonamiento epistémico deriva de los principios normativos de la lógica y demás teorías formales (Samuels, Stich y Bishop, 2002: 237). $\mathrm{Y}$, como la idea esencial es que esas reglas sirven de guía normativa y pueden dar recursivamente cuenta del buen razonamiento o juicio racional humano, parece apropiado designar como razones epistémicas a aquellas razones fundadas para creer que.

En tanto que particiones limpias ${ }^{1}$, estas categorías se han mostrado particularmente útiles para identificar las distintas posiciones en juego y disolver sus discrepancias en un lenguaje conceptual compartido. Así, en un breve epílogo final, podrán retomarse para revisar críticamente su utilización desde los lineamientos del paradigma integrador al que se enfrentan las ciencias sociales a comienzos del nuevo milenio (Barkow, 2006; Gintis, 2009; Weingart et al. [eds.], 1997).

1. Se trata de una partición formalmente correcta, puesto que las tres categorías constituyen dominios enteramente distintos (causas estructurales objetivas y razones subjetivas). Son, además, mutuamente excluyentes, ya que ningún elemento de uno de los conjuntos cae simultáneamente bajo dos conceptos clasificatorios distintos (así, por ejemplo, una causa estructural no puede ser a la vez cognitiva y sociológica), y respectivamente exclusivos puesto que, aun difiriendo entre sí, las distintas variantes o modalidades de un conjunto (causas cognitivas innatas o adquiridas, por ejemplo) retienen algún rasgo fundamental del mismo (causas endógenas). 


\section{Supremacía indiscriminada de las causas sociológicas}

Muchas de las instituciones europeas del saber filosófico y humanístico se vieron seriamente afectadas o fueron directamente desmanteladas durante el periodo de entreguerras en la primera mitad del pasado siglo. Buena parte de esa actividad pasó a los Estados Unidos de América, donde se propició el surgimiento de nuevas corrientes de pensamiento. Con la idea de conciliar lo más granado de las tradiciones fundacionales, Talcott Parsons (1937) avanzó entonces su proyecto de síntesis teórica, una idea de coloso finalmente reducida a un complejo sistema conceptual construido en torno a la noción de rol. Fundado sobre el comportamiento institucionalmente normado, su modelo de equilibrio social acabó supeditando a causas sociológicas las razones fundadas que — supuestamente- mueven a los sujetos.

\section{El fatalismo de los roles sociales}

A pesar de lo profuso - y confuso- de su obra, su trabajo puede recogerse en tres síntesis elementales relativas a la estructura normativa de la acción, el papel de las instituciones y los roles en la diferenciación y estratificación social y, finalmente, al equilibrio funcional del sistema social. En la primera síntesis, Parsons (1937) reconsidera las propiedades del modelo económico neoclásico, al que, de propia cosecha, añade una indeclinable orientación normativa. Así, además de las restricciones del conjunto de oportunidad y de la capacidad de anticipación supuesta al agente económico, su definición del «acto unidad» incorpora un criterio normativo de elección ilustrado desde normas y valores colectivamente consensuados. A partir de ahí, la omisión de cualquier referencia explícita a la arquitectura social de la mente o a una idea alternativa de trasfondo ${ }^{2}$ hace que Parsons acabe comprometiéndose con la analogía organicista durkheimiana y su tesis del cerebro de grupo, y asigne a causas sociológicas la función explicativa única de su sistema teórico.

Con preferencias así subordinadas a factores estructurales exógenos (valores, normas e instituciones), su segunda síntesis (Parsons, 1951) establece los principios de diferenciación (la teoría de los roles de adscripción y realización) y desigualdad social (su teoría de la estratificación social), respectivamente. En ambos casos, el teorema del «fatalismo de los roles» (su inevitabilidad y complementariedad) hace que el comportamiento individual se ajuste o se adapte a una asignación institucional (de bienes, personal y estatus) conforme a los recursos disponibles (contexto de escasez) y a una interpretación normativa colectivamente consensuada. Serán esos principios de asignación e interpreta-

2. La tesis del trasfondo desarrollada por el filósofo analítico John Searle (1995: 139-158) a propósito de su especulación sobre los «hechos institucionales», remite a un conjunto de capacidades o estructuras cognitivas preintencionales que hacen determinados estados mentales posibles. En relación con esta idea también el sociólogo P. Bourdieu $(1980,1984)$ ha hecho una aportación interesante (ver inciso 3.3. a propósito de su noción de habitus). 
ción los que pauten las interacciones sociales dentro de sistemas de roles e instituciones que pasan entonces a tener una clara prioridad sobre las preferencias o los estados mentales individuales.

Su tercera síntesis presenta al «sistema social» como un todo emergente constituido por cuatro subdominios de acción en constante intercambio funcional. Con información específica propia, cada uno de ellos mantiene su autonomía relativa y cuenta con contrapartidas institucionales que lo equilibran horizontalmente en razón de imperativos funcionales específicos, sea de «adaptación» (esfera de la economía), «logro de fines» (esfera social de la interacción), «integración» (esfera política y del derecho) o «latencia» (esfera de la cultura depositaria de valores y normas colectivos), respectivamente. El equilibrio sistémico global, en cambio, atiende a un doble movimiento vertical que asciende desde los niveles más proteicos o ricos en necesidades (esfera de la economía) hasta alcanzar el nivel superior de la conciencia colectiva (esfera de la cultura), para descender luego desde esa esfera rica en valores e intereses comunes y distribuir información consensuada a lo largo de los restantes subdominios. Así, a partir de insumos informativos procedentes de la esfera externa de las necesidades individuales objetivas, la información se mueve hasta alcanzar resultados consensuados que prefiguran el criterio (o los criterios) normativo que debe regir a los comportamientos colectivos o sociales. Como en una suerte de mecano o termostato, los insumos informativos externos (necesidades procedentes del medio) llevan a resultados endógenos (información programada desde el sistema) que autorregulan funcionalmente el sistema social en un equilibrio cibernético de consenso.

\section{La deriva de la sociología norteamericana}

Las reacciones generales a esta versión hipernormada de la vida social fueron muchas y variadas. Si bien en ciertos medios europeos la tesis de los roles sociales se acogió con relativa simpatía (Dahrendorf, 1958), en su círculo más próximo fue comúnmente rechazada. Su desmedida pretensión acerca de las posibilidades teóricas de la disciplina (Merton, 1949), su alambicamiento argumentativo y vacuidad empírica (Mills, 1959), su artificiosidad conceptual (Homans, 1961) y la refutación empírica de su tesis central de que el consenso engendra consenso (Gouldner, 1970), desdoraron prontamente todo éxito aparente. Además, la constatación de que los roles pueden contraponerse, resultar ambiguos o ser contradictorios, llevó a pensar que ese concepto «bóveda» de la síntesis parsoniana estaba mal definido, lo cual dio paso inmediato a versiones «dramatúrgicas» (Goffman, 1972) y «estratégicas» (Boudon, 1979a: III) del mismo. El rol quedó, así, reducido a una categoría menos básica que las razones epistémicas o el cálculo racional de quienes intencionalmente lo interpretan o gestionan.

Seguramente, la consecuencia más desastrosa fue la huida masiva de muchos sociólogos angloamericanos a formas dispersas del trabajo aplicado (cualitativo o cuantitativo) que pasó a caracterizar buena parte de la investigación socio- 
lógica de los tempranos cincuenta. Una reacción que hizo pendular a la disciplina entre una mera sociografía descriptiva (estadística o hermenéutica) y una sociología teórica pobre y vacilante, y la convirtió en un área de estudio aislada, disgregada y pluriparadigmática.

\section{La preeminencia de los procesos subjetivos: el construccionismo social}

Otro efecto inesperado del desproporcionado énfasis del estructuralismo funcionalista en las causas sociológicas fue un creciente empeño en recuperar las motivaciones del sujeto. Al margen de la ya larga tradición interaccionista de Chicago, nuevos intentos de sociología subjetiva pasaron a cobrar relevancia gracias a la influencia indirecta de Alfred Schütz, un refugiado austríaco confinado en la New School for Social Research (Nueva York), cuya versión sociológica de la fenomenología de Edmund Husserl (1859-1938) acabó convirtiéndose en semillero de nuevas "sociologías creativas».

Entendida como "ciencia de lo que aparece en la conciencia», la fenomenología de Husserl se construye en torno a la "conciencia reflexiva» centrada en las "unidades ideales de significado" y concibe al conocimiento como proceso de "autoexploración». Para Husserl, la conciencia (o «yo trascendental») que da fundamento a los actos intencionales es "constitutiva», y las demás realidades (no constituidas) se dan como «las cosas mismas» en esa intención esencial. De ahí que su fenomenología pretenda reabsorber en el «yo que constituye» todas las demás realidades y pase a entender la intersubjetividad, no como una cuestión de conocimiento objetivo y válido para todos, sino como el reconocimiento mutuo de los sujetos que precede a la constitución de lo real. Puesto que lo que es cognoscible para un yo lo es también para otros, «intersubjetividad» y «endopatía» acaban así asociándose hasta permitir que, en «el flujo de lo vivido" por una multiplicidad indefinida de sujetos, se dé una "comunidad intersubjetivamente idéntica» y en estado de entendimiento y comprensión mutua (su noción central de «mundo de la vida»).

Si bien Schütz (1932: 97) manifiesta expresamente su intención de alejarse de la preocupación fenomenológica de Husserl por los procesos mentales, buena parte de su propuesta se desmonta si se toma fuera de ese marco de referencia. Así, aun dejando de lado los procesos cognitivos conscientes y exteriorizando y haciendo girar la comprensión interna del ego trascendental en torno al mundo intersubjetivo, su concepción continúa centrada en «aquella interacción en la que se capta la subjetividad del otro al tiempo que se vive el flujo de la propia conciencia» (Natanson, 1973: xxxii).

A pesar de su aislamiento de los círculos académicos locales, su expresa beligerancia con el sociologismo y el conductismo social facilitó su integración en la tradición sociológica norteamericana. Bien es verdad que solo lo logró después de su muerte, y en gran medida gracias a la traducción y adaptación de su obra por sus inmediatos discípulos. Pero, para mediados de los sesenta, su descripción fenomenológica del mundo social se había difundido ampliamente y ganado una presencia masiva en las aulas de sociología. 
En la versión sociológica de Peter Berger y Thomas Luckmann (19661968), las ideas de Schütz pasaron a referirse directamente a la esfera mundana de la vida cotidiana tomada como reducto último de sentido del «mundo de la vida", el locus donde la intersubjetividad se da gracias a la sociabilidad o simultaneidad del flujo de conciencia con otros. En efecto, cuando la gente interactúa en el contexto cotidiano, lo hace con el convencimiento de que sus respectivas percepciones de la realidad se relacionan. Y, al actuar sobre esta base de entendimiento compartido, su conocimiento común de la realidad se refuerza hasta llegar a precipitarse en tipificaciones, roles e instituciones que pasan a constituir parte de la realidad objetiva. Es gracias a este proceso de objetivación o institucionalización que, mediante el flujo de lo vivido por una comunidad en estado de comprensión mutua, se acaba injertando significado a las estructuras sociales.

Lejos, pues, de la idea filosófica de conciencia interior trascendental, en la vulgata sociológica la intersubjetividad acaba cristalizando en un vivir humano socialmente indexado al ámbito mundanamente subjetivo de la interacción cotidiana. $\mathrm{Y}$ es en ese "ámbito mundanamente subjetivo de lo cotidiano» en el que, bajo el único peso restrictivo de las estructuras socioculturales heredadas (tipificaciones e instituciones), los hombres crean socialmente su propia realidad (Berger y Lukman, 1966-1968: 61). De este modo se acaba fundamentando la tesis del "construccionismo social», una idea que posteriormente adoptaron muchos más y que, en sus versiones más duras y restrictivas, terminó extendiéndose hasta abarcar los hechos objetivos de la ciencia. Es entonces cuando, partiendo del supuesto de que lo «real» y lo «irreal» son meramente cuestiones de entendimiento o convención social (Latour, 1979), los hechos objetivos pasaron también a ser descritos como parte exclusiva del proceso subjetivo humano. Y, puesto que, para estos autores, la única evidencia del mundo son los significados intersubjetivos, la realidad exterior se desvanece hasta acabar negando la existencia del mundo objetivo.

Ajenas a grandes pretensiones explicativas, las distintas variantes del constructivismo social (sociofenomenología, sociología existencial y fenomenología) han tenido como objetivo inmediato la descripción del hombre en el mundo. De este modo, solo algunas técnicas de introspección e interpretación obran como su aportación mejor conocida, y los significados, la producción de situaciones sociales, el interés por las formas y los procesos que constituyen objetivamente e instituyen subjetivamente las estructuras de la realidad cotidiana como sus rasgos comunes más significativos.

\section{Universales humanos y causas cognitivas: El intercambio mente-medio}

Contrariamente a lo expresado por Merton (1938) en su famoso ensayo sobre estructura social y anomia acerca de la irrelevancia de la psicología y la ciencia biológica para la sociología, los intentos de explicaciones funcionales inmediatamente posteriores hicieron servir ideas importadas de ambas disciplinas para intentar respuestas convincentes acerca de la interacción entre mente y 
medio. Una preocupación que acabó condensándose en la búsqueda de los universales humanos, de aquellas estructuras cognitivas que, junto con las causas sociológicas y las motivaciones conscientes, se creía formaban parte de la explicación de los comportamientos sociales.

Aunque los universales pueden encontrarse en los individuos, la sociedad o la cultura, hoy sabemos que es inútil y poco razonable considerarlos de forma independiente o aislada. Es evidente que nada de la cultura humana es o se transmite si no es a partir de una constitución genética evolutivamente cribada. Pero también es innegable que muchos aspectos significativos de la anatomía y la fisiología humanas solo pueden entenderse tomando en cuenta la cultura, parte crucial del medio en el que interactúan los genes para producir los organismos humanos. Con ello, al pensar en universales, se impone la búsqueda de marcos de intercambio entre naturaleza y cultura capaces de dar cuenta de la combinación adecuada de ambos factores.

Cabe decir que las condiciones de época y la falta de herramientas conceptuales apropiadas prolongaron la espera de una solución satisfactoria a este respecto. Así, a lo largo de los siguientes apartados se hilarán algunas de las propuestas más salientes, partiendo de las primeras teorías del intercambio de los años sesenta hasta llegar a la revolución de las ciencias cognitivas y el desarrollo de la psicología evolucionaria moderna. A través de ese recorrido se podrá apreciar cómo solo recientemente se ha logrado llegar a una concepción más ajustada del intercambio Nature/Nurture (o naturaleza/crianza), una de las piezas cruciales en la resolución del complejo rompecabezas de las ciencias sociales.

\subsection{La perspectiva ecológica: la selección por refuerzo}

Aunque George Homans se había iniciado como diletante en las tertulias intelectuales de los antropólogos socioculturales de su tiempo, su compromiso inmediato con el trabajo de campo le llevó a convencerse de que una misma e idéntica naturaleza humana se reiteraba a lo largo de las distintas épocas y lugares. Convencido de que el problema central de la sociología era precisamente no haber atendido a estos universales, se propuso subrayar los límites del relativismo antropológico y cultural empeñado en marcar las diferencias, al mismo tiempo que rebatir sistemáticamente los postulados apsicológicos del funcionalismo estructural y la tesis concomitante de la operación exclusiva de las causas sociológicas.

En su intento por recuperar la base psicológica universal del comportamiento humano, creyó reconocer, en la psicología intuitiva de las creencias, o Folk Psychology (Mundó, 2006), y en el interés de los individuos por satisfacer su compleja red de necesidades, la reacción natural o innata del intercambio social. Para garantizar además el carácter reiterado de las consecuencias de dicho comportamiento, adoptó de la psicología conductista el patrón o mecanismo de selección por refuerzo. Así acabó entendiendo el intercambio humano como «un intercambio de actividad [...] más o menos gratificante o cos- 
tosa, entre, al menos, dos personas [que buscan el interés propio]» (Homans, 1961: 13).

A partir de esa base elemental, construyó un sistema de postulados llamados a dar cuenta de aquellos patrones regulares que alientan la acción humana (su proposición de la racionalidad) y, de forma lateral, consolidan el tipo de preferencias que acarrean buenas consecuencias (proposición del estímulo) dentro de determinadas formas de intercambio. Pasó entonces a concebir a los agentes sociales como individuos que atienden a cálculos elementales de coste-beneficio y se mueven por intereses individuales (la tangente económica) y, a la vez, naturalmente inclinados a retener (supuesto cognitivo no atendido más allá de reacciones instintivas elementales) los comportamientos que les resultan gratificantes (la tangente conductista).

Por lo que respecta al análisis de las instituciones, pretendió desmarcarse del funcionalismo estructural mediante su defensa de la base psicológica de las instancias colectivas (Homans, 1974). Al suponer que lo que se selecciona por efecto del refuerzo son determinados tipos de preferencias maximizadoras, la cristalización de comportamientos gratificantes bien puede explicar el hecho social emergente. De este modo, pasó a entender las instituciones, no como obra de fuerzas supraindividuales ajenas al individuo, sino como resultado de una concatenación de pautas psicológicas universales supeditadas a distintos estímulos cribados mediante mecanismos contextuales de refuerzo.

Mérito suyo es haber intentado recuperar los hechos mentales y reemplazar la noción estructural de rol por una noción psicológica más refinada de comportamiento intencional. Pero, su teoría del intercambio contenía defectos de base que pronto la inutilizaron. Si bien la idea de que «todos los ejemplos normales de fenómenos sociales emergentes [pueden] explicarse fácil y rápidamente partiendo de proposiciones psicológicas» era básicamente correcta, al ignorar las discrepancias de fondo entre la psicología de las creencias que subyace a sus tesis económicas y la psicología conductista del refuerzo que también incluye, introdujo en el núcleo de su propia conjetura explicativa la dificultad de compatibilizar historias causales en cierta medida opuestas. En efecto, mientras la Folk Psychology, una teoría básicamente intencional, explica las acciones por recurso a estados mentales internos (creencias, deseos, preferencias), la psicología conductista rechaza explícitamente la idea de comportamientos causados endógenamente y apela únicamente a estímulos procedentes del medio. Sabido es que, para los conductistas, los estados mentales son «meras reminiscencias de mitos conjurados» (Watson, 1930: 2-5), una suerte de "metafísica cuya existencia depende exclusivamente de nuestra ignorancia» (Skinner, 1971: 12). E incluso en aquellos casos en los que resulta imposible eliminarlos, los estados mentales no pueden representar más que variables dependientes o no explicativas. Se trata de una restricción esencial del conductismo, la tesis sobre la que hace pivotar su interés por la relación funcional entre conducta y medio y de la que depende que los resultados de una determinada conducta pasen a gobernar los comportamientos ulteriores del sujeto (o «ley del efecto»). 
Al tratarse de concepciones básicamente incompatibles, una de las dos tenía que acabar sucumbiendo. Así, a la postre, Homans supeditó la conducta social a estímulos ecológicos y la hizo producto de una selección por refuerzo. Si al menos se hubiera informado mejor, probablemente no habría incurrido en ese tipo de fallos. Pero no solo hizo caso omiso de tales diferencias, sino que también ignoró cualquier referencia a los profundos cambios que se estaban dando en la psicología de su tiempo. Desatendió así cuestiones tan vitales como el agrio proceso de Chomsky contra Skinner a propósito de la naturaleza de los procesos mentales implicados en el aprendizaje del lenguaje. Mientras, por analogía con el proceso evolutivo que selecciona consecuencias adaptativas a través de sucesivas variaciones hereditarias, la selección por refuerzo había servido a Skinner (1957) para explicar el aprendizaje en función de la reiteración de conductas gratificantes ${ }^{3}$, para Chomsky se trataba de un planteamiento enteramente distinto. De hecho, en el caso de la selección natural, lo que se criba directamente no es la estructura del órgano (el corazón, el ojo, etc.), sino los genes (información) que sirven para codificarlo. Y, precisamente, en el caso del conductismo operante, se echaban a faltar las instancias (mecanismos o módulos) de información codificada que permiten el aprendizaje del lenguaje. Al omitirlas, el operacionalismo conductista se mostraba esencialmente incapaz de superar el nivel de la correlación entre estímulo y respuesta. Pero, implicarlas, habría supuesto admitir también algunos principios básicos acerca del sistema cognitivo humano. Y es ahí donde incide la crítica de Chomsky.

En contraste con la concepción conductista de la mente como mero reservorio de estímulos procedentes del medio, la psicología cognitiva equipara la mente a un potente procesador de información provisto de programas endógenos capaces de discriminar entre estímulos y organizar respuestas. Una idea envolvente que, sin necesidad de hacer expresos los estados mentales de la psicología común, permite circundarlos y, a la vez, ligar los estímulos o variables ecológicas o ambientales a una estructura cognitiva dotada de módulos informativos capaces de reconocerlos, procesarlos e inducir las respuestas adecuadas de intercambio. Una tesis potente sobre causas cognitivas que podría haberle abierto a Homans líneas de aproximación mucho más interesantes y fecundas que las tablas conductistas de refuerzo ${ }^{4}$.

3. El razonamiento de Skinner es que, si hablamos gramaticalmente, es porque esa conducta ha sido positivamente reforzada en el pasado y, por consiguiente, recurre de nuevo en el presente.

4. Tampoco se comprende muy bien por qué obvió los desarrollos de la matemática de juegos y de la racionalidad estratégica introducidos una década antes por Von Newman y Morgenstern (1947). Así, mientras su modelo de coste y beneficio arrastró las restricciones de la racionalidad paramétrica, otros, inmediatamente después, lograrían combinar con éxito la racionalidad estratégica y los formalismos de juegos con principios biológicos para describir la evolución del comportamiento social. 


\subsection{La perspectiva lingüistica: gramáticas del inconsciente}

También en los círculos francoparlantes se configuró un eje alternativo de debate sobre los universales humanos, en este caso fuertemente influido por Ferdinand de Saussure (1925) y su concepción de la lengua como un sistema cerrado o una estructura arquetípica preadaptada a la comunicación lingüística. En contraste con el hecho individual del habla, la lengua se presentaba como un fenómeno social cuyas reglas constitutivas permitían a los hablantes de una comunidad lingüística entenderse entre ellos. En ese sentido, la lengua pasó a verse como la condición previa al uso que de ella hacen los hablantes. Una propuesta que revolucionó la perspectiva analítica hasta entonces vigente y se convirtió en una nueva y provocativa forma de enfocar también el estudio de las sociedades humanas. El llamado «método fonológico» llegó a cobrar tanta fuerza en el campo de las ciencias sociales y de la cultura que, más que como sujeto de aprendizaje, socialización e historia, el hombre pasó a concebirse en clave de estructuras endógenas y objetivas (causas cognitivas).

Máximo representante de esta corriente, y uno de los más prominentes fundadores de la antropología moderna, Lévi-Strauss dio al término «estructura» una fuerte connotación lingüística y de comunicación, asociándola a aquella «gramática del inconsciente» que capacita, a la vez que restringe, el abanico de posibilidad empírica de configuraciones socioculturales (su tesis de una naturaleza humana finitamente maleable). Más que discriminar entre ciencias naturales o sociales, para él, el sentido crucial de la lingüística era ofrecer una perspectiva capaz de conectar la psicología con la neurología. Y, aunque enterado de las disputas en auge en la sociobiología de su tiempo, se mostró renuente a admitir la significación evolutiva de los atributos culturales como clave para comprender el lenguaje y la significación simbólica ${ }^{5}$ que pasó a entender como sistemas de comunicación supeditados a reglas sintácticas universales.

Siguiendo las pautas del procedimiento fonológico, centró entonces su atención en la búsqueda de aquellos universales responsables de los efectos observados en sus investigaciones de campo. Así, en su conocido estudio de los mitos (1964), descifró un puñado de leyendas primitivas con contenidos dispares en términos de una única y misma gramática (Sperber, 1968). Y hasta tal punto llevó la analogía, que hizo diferir mitos y lengua por el solo hecho de que, en lugar de fonemas (o unidades básicas del habla), vio los mitos como compuestos de «mitemas» (o unidades mínimas de significado). De forma parecida se aproximó analíticamente al núcleo de las culturas humanas que pasó a describir en función de reglas innatas causalmente sensibles al entorno y capaces de prefigurar el espacio de alternativas de comunicación e inter-

5. Conforme al testimonio del propio Wilson (1994: 328), con la salvedad de entenderla en términos del comportamiento prelingüístico, Lévi-Strausss «creía que la sociobiología era correcta en el noventa por ciento [de sus afirmaciones]». Para él, el pasaje de la naturaleza a la cultura, como cuando se usa el lenguaje, se aprende a cocinar, etc., obedece a leyes que el hombre no inventa, sino que, más bien, responden a mecanismos del cerebro humano. 
cambio conceptualmente plausibles. Así, en su estudio de las estructuras elementales del parentesco, subordinó la circulación de mujeres y el intercambio sexual a ciertas reglas innatas de sabiduría genética, que, como la exogamia y la evitación del incesto, hacen a los individuos causalmente sensibles a determinadas formas de intercambios de pareja.

Pero, aunque necesarias, esas reglas sólo se activan mediante el impacto concomitante de la cultura. De ahí que su explicación de la circulación de mujeres haga referencia, por una parte, a estructuras objetivas que en el nivel sincrónico ${ }^{6}$ habilitan o capacitan para determinadas formas de comunicación e intercambio de parejas. Pero, por otra, igualmente, aludan a prohibiciones - circunstanciales e históricas - que permiten dar cuenta de las variaciones diacrónicas empíricamente observadas. De esta forma, sin omitir el impacto de la cultura, serán las estructuras reactivas o capacidades objetivas de dominio universal las que constituyen el núcleo duro de su propuesta analítica.

$\mathrm{Al}$ intentar explicar en términos de estructuras elementales tales como «la disposición innata a seguir ciertas reglas», «la norma de reciprocidad» y «los vínculos entre quienes dan y quienes reciben dádivas o regalos», Lévi-Strauss aporta una visión innovadora de cómo trabaja la mente humana, a la vez que se aleja sustancialmente de otras teorías del intercambio. Parece natural que al concebir las estructuras sincrónicas u objetivas como gramáticas no conscientes, le resulte inadmisible tomarlas como producto de intercambios egoístas o resultado de cálculos maximizadores. Serán también sus propios supuestos los que le lleven a rechazar cualquier tesis que las presente como producto funcional de una selección por refuerzo, o las haga depender de estímulos ambientales o sociales externos. De ahí su frontal discrepancia con Homans y el conductismo social (Ekeh, 1974) y su continuada animadversión hacia el funcionalismo estructural.

La crítica decisiva al método fonológico asociado al estructuralismo lingüístico llegaría de la mano de las ciencias cognitivas modernas, una perspectiva multidisciplinaria capaz de proveer una concepción materialista bastante más precisa de los procesos cognitivos y las estructuras mentales innatas. La innovadora idea de la mente como un complejo procesador de información permitió a los psicólogos cognitivos concebir los procesos mentales, no solo como representaciones, sino también como computaciones de representaciones. Concepción que de inmediato dio paso a un complejo programa de investigación en el que el lenguaje computacional acabaría unificando conceptualmente distintos universos de estudio. A partir de ahí, las indagaciones sobre la mente humana se pusieron bajo el escrutinio conjunto de la investigación psicológica, lingüística, filosófica y biológica, de la neurociencia, la robótica y la inteligencia artificial. Un trabajo interdisciplinario que hizo posible la

6. Se trata de otra de las dualidades metodológicas típicas de Saussure, que entiende por sincronía el eje atemporal de simultaneidades o de las relaciones entre elementos coexistentes, y por diacronía, el eje de sucesiones relativo a las distintas maneras en las que se presenta un elemento a lo largo del tiempo, su evolución. 
formulación de tesis más precisas acerca de la estructura de la mente y el funcionamiento de la cognición humana, al tiempo que facilitó la contrastación de conjeturas cruciales acerca de sus modos de operar.

En efecto, gracias a la revolución de las ciencias cognitivas el estudio de la mente alcanzó una base de objetividad y credibilidad a la que ninguna otra concepción anterior había logrado llegar. Al centrar el estudio de la mente en su poderoso sistema informativo (o software), pudo prescindir también de descripciones pormenorizadas del cerebro (la máquina física o hardware sobre la que se monta) y abandonar su estudio separado del lenguaje. Y, una vez que se entendió este último como una ventana más que se abre sobre la compleja arquitectura cognitiva humana, la concepción lingüística previa queda desmontada. Fue así como el estructuralismo lingüístico perdió su antigua fuerza y fundamento y pasó a derivar en un movimiento heterogéneo y con figuras tan conocidas y controvertidas como Foucault (análisis del discurso), Lacan (psicoanálisis) y Althuser (revolución sin sujeto), hasta acabar diluyéndose con el tiempo.

\subsection{El habitus: Capacidades adquiridas de trasfondo}

Aunque no cabe duda de que Pierre Bourdieu está en deuda con el pensamiento antropológico de Lévi-Strauss ${ }^{7}$, en su reconstrucción sociológica se aleja de él para asumir una modalidad de estructuralismo genético» ${ }^{8}$. A semejanza de los universales humanos entendidos como capacidades innatas, también Bourdieu supone que el habitus actúa «a condición de reencontrar a los agentes ya condicionados para reconocerlos" (1980: 93). Pero, a diferencia de los universales de la primera generación, él hará referencia a un conjunto de estructuras cognitivas que funcionan en presencia de determinadas "posibilidades e imposibilidades, libertades y necesidades, facilidades y prohibiciones $[\ldots]$ inscritas en las condiciones objetivas» (op. cit.: 94). Todo ello hace que entienda el habitus "no como un destino", sino como "producto de la historia", un sistema abierto de disposiciones que se reactiva continuamente y hace referencia a rasgos generales de la cultura humana que se adquieren a lo largo de prácticas y experiencias reiteradas dentro de un campo.

Duradero pero no inmutable, el concepto de habitus aporta una innovadora aproximación a la idea de trasfondo común o intencionalidad colectiva ${ }^{9}$.

7. «La dialéctica del sentido de la lengua y las "palabras de la tribu” es un caso particular y particularmente significativo de la dialéctica entre los habitus y las instituciones» (Bourdieu, 1980: 99).

8. Inspirado en las estructuras psicológicas o cognitivas de Piaget, el término «estructuralismo genético» es adoptado por Lucien Goldmann para hacer referencia al método de análisis cultural centrado en las estructuras mentales significantes, entendidas en términos de su origen en procesos históricos y sociales.

9. Además de la intencionalidad individual, estos universales militan a favor de una intencionalidad colectiva, respecto de la cual John Searle se muestra mucho más resolutivo: «La intencionalidad colectiva es un fenómeno biológico primitivo que no puede ser reducido a, o eliminado a favor de, otra cosa» (1995: 41-42). 
En efecto, lejos de presentar los hábitos como contenidos intencionales compartidos, Bourdieu los trata como precondiciones genéricas, «fuerzas inscritas» (op. cit.: 96) que hacen referencia a la «realización de [...] esencias preexistentes» y que llegan a formar parte del sistema de cogniciones y creencias de grandes grupos humanos. Objetivamente ajustados a la lógica característica de un determinado campo, los hábitos «reproducen las regularidades inmanentes a las condiciones [...] de su principio generador», y se ajustan a «las exigencias inscritas como potencialidad objetiva en cada situación» (op. cit.: 97). $\mathrm{Y}$, en tanto propician cogniciones familiares y formas mecanizadas de respuesta, en un sentido constitutivo o de condición previa, preceden a la práctica humana y potencian a la vez que restringen su abanico de posibilidad empírica. Se trata, pues, de «estructuras estructuradas» que son activadas por las "prácticas o experiencias reiteradas dentro de entornos reincidentes" que "hacen posibles» determinados estados de cognición colectiva (ibídem).

$\mathrm{Al}$ asumirlos como estructuras objetivas, Bourdieu no está pensando en tendencias estadísticas que sirven para describir cómo determinados productos de la mente acaban poblando masivamente las mentes de grandes agrupaciones humanas. No se trata de simples agregados. Son hechos emergentes, estructuras cognitivas que, dentro de determinados esquemas generativos de percepción, aseveración y acción, hacen referencia expresa a predisposiciones constitutivas o capacidades inmanentes que resultan sensibles a las reglas o exigencias objetivas de la situación (o campo). Y, en tanto precondiciones cognitivas, los hábitos funcionan causalmente haciendo posibles determinados estados intencionales colectivos. Es así como, en su empeño por superar la oposición tradicional entre subjetivismo y objetivismo, Bourdieu avanza una concepción unitaria de individuo y sociedad condensada teóricamente en sus dos nociones complementarias de «habitus» y «campo».

Por campo entiende el sistema de relaciones sociales definido por la posesión y producción de una forma específica de «capital» (objetivo, simbólico u otro) dentro del cual operan las convenciones, normas e instituciones que definen sus reglas específicas. De hecho, cada campo posee una estructura autónoma en la que las posiciones de poder y subordinación relativas dependen del contenido de sus propias reglas. Tomadas en conjunto, las redes recíprocas de influencia intercampos dan lugar a la estructura social global que, aunque retiene el principio clásico de desigualdades y asimetrías sociales, no las entiende como contradicciones de clase (Marx), o posiciones necesarias (Parsons), ni como estratos continuos en una gradación de posesiones (Davis y Moore), sino como relaciones de dominación-subordinación fijadas por la posición objetiva de los individuos dentro de los distintos campos. Esas estructuras sociohistóricas van siempre acompañadas de esquemas cognitivos o hábitos propios, de forma tal que, a cada posición objetiva dentro del campo, corresponde también un sistema subjetivo de expectativas y predisposiciones, un habitus adquirido a través de vivencias compartidas y prácticas reiteradas dentro del mismo. De esta manera, el habitus acaba respondiendo al conjunto de capacidades reactivas o generativas de percepción, aseveración y acción incor- 
poradas al proceder habitual de la gente dentro de determinados contextos socio-históricos o campos. Y, en tanto referido a patrones mentales o recursos cognitivos comunes sensibles al entorno, predetermina el espectro dentro del cual un colectivo percibe el mundo y actúa sobre él.

Ninguno de los paradigmas heredados de explicación social, ni el de las causas sociales exógenas (del funcionalismo conductista o estructural), ni el de la intencionalidad (por supuesto no el de las sociologías subjetivas, pero tampoco el de la teoría de la elección racional) le parecen capaces a Bourdieu de dar cabal cuenta de la relación entre el comportamiento humano y la estructura social: "Escapando de la disyuntiva de las fuerzas inscritas en [...] el exterior de los cuerpos, y las fuerzas interiores, motivaciones surgidas instantáneamente de la libre decisión, las disposiciones interiores, interiorización de la externalidad, permiten a las fuerzas exteriores ejercerse, pero según la lógica específica de los organismos en los que están incorporadas [...] de manera duradera, sistemática y no mecánica. Sistema adquirido de principios [schèmes] generadores, el habitus hace posible la producción libre de todos los pensamientos, todas las percepciones y acciones inscritos dentro de los límites que marcan las condiciones particulares de su producción, y sólo éstas" (op. cit.: 95-96). En este sentido, su idea del habitus o conjunto de capacidades reactivas o generativas de percepción constituye un principio alternativo de causación y abre una posibilidad analítica interesante a la coordinación entre estructura y acción.

Aunque deja sin argumentar cómo esas habilidades o capacidades reactivas resultan causalmente sensibles a los contenidos específicos de las reglas de los distintos campos, su idea de los universales humanos como un conjunto heterogéneo de causas cognitivas, no solo innatas y procesuales, sino también sustantivas y experienciales ${ }^{10}$, hace que su propuesta escape al grueso de las críticas dirigidas contra el estructuralismo lingüístico y alcance una aceptación generalizada relativamente importante.

\subsection{La perspectiva genética: el mecanismo de la selección natural}

Con la transformación, en 1976, de un programa de investigación sobre comportamiento ecológico en otro de sociobiología, Patrick Bateson (1982) de la Universidad de Kin (Cambridge, Massachusetts) introducía una distinción importante. Los estudios funcionales del comportamiento social dejaban de tener un carácter necesariamente ecológico (exógeno) y podían hacerse de forma más eficiente desde la perspectiva genética (endógena). Aunque ambas formas de explicación, genéticas (evolucionarías o de selección natural) y ecológicas (no evolucionarias o de selección por refuerzo), no suelen avenirse en

10. Brown (1991: 42-43) ilustra así la distinción que hace Chomsky en lingüística (1965: 27 30) y Fox en antropología (1989: 113) entre universales "sustantivos» (aquellos que evocan los antropólogos con mayor frecuencia) y universales "procesales», innatos y de dominio universal (biológicos), mucho más significativos que los anteriores, aunque no siempre se expresen en alguno de ellos. 
principio, está claro que cualquier explicación ecológica buena acaba siendo compatible con algún tipo de interpretación evolucionaria, aunque no a la inversa.

A pesar de las grandes controversias que inicialmente desató la perspectiva genética (Segersträle, 2000), son muchos los autores que, en épocas recientes, han llegado a creer que las explicaciones evolucionarias permiten eliminar ciertos errores recurrentes en la forma de pensar acerca de la evolución del comportamiento. En efecto, una rigurosa perspectiva genética ayuda a evitar falacias morales, ya que permite identificar y manejar aquellos debes que contradicen la realidad, al mismo tiempo que alienta la formulación de predicciones sustantivas contrastables, incluso en el caso de la conducta humana. Así, muchos han usado este procedimiento para predecir efectos del contenido informativo en el razonamiento lógico (Cosmides, 1989), diferencias de género en habilidades perceptuales (Silverman y Eals, 1992), acerca de nuestra capacidad de llegar a imágenes corporales (Stingh, 1993), o a identificar atajos intuitivos o pautas alternativas de razonamiento que permiten extender el concepto de racionalidad a heurísticas de la inteligencia del inconsciente (Gigerenzer y Selten, 2002; Gigerenzer, 2007), etc.

Aunque la naturalización de la mente y las sociedades humanas apenas si tiene cabida en los manuales o textos habituales de sociología, la perspectiva genética se ha ido imponiendo en las demás ciencias sociales y del comportamiento, con lo que ha tendido a convertirse en una matriz rica en expectativas experimentales y orientaciones teóricas (Barkow, 2006: 11). Pero, gracias a su tradicional aislamiento y amparados por su "trained incompetence» (Lopreato, 1999: XI-XIII), muchos sociólogos se resisten a aceptar las profundas modificaciones impuestas por los avances de la biología evolucionaria. De hecho, buena parte de la práctica disciplinaria continúa aferrada al dominio de las causas sociológicas y las motivaciones subjetivas, e «incapaz de enfrentarse al formidable reto que le viene de fuera». Aunque algunos se sienten inconformes con esta situación, «la gran mayoría continúa encontrándose razonablemente cómoda haciendo aquello que están acostumbrados a hacer. Y, mientras tanto, la crisis de la disciplina se ahonda debido a la ausencia de principios generales que sirvan de guía a la investigación y provean una lógica estable a la organización teórica de sus hallazgos» (op. cit.: 21-22). Pero tales principios existen y forman parte del núcleo de la revolución que ha experimentado el conjunto de las ciencias de la mente y del comportamiento en las últimas décadas.

Ninguna otra teoría ha puesto un límite a las teorizaciones tradicionales tanto como la de Darwin. Ha dañado profundamente las argumentaciones teológicas acerca de la existencia de un creador o un diseñador y puesto fin a muchas especulaciones sobre el propósito del universo, el significado de la vida y la naturaleza del hombre, reconsiderando también los fundamentos de la sociabilidad y la moralidad humanas (Dennett, 1995). Metodológicamente, además, se ha convertido en un punto de inflexión en el modo de construir teorías. Ha aportado no solo estrategias alternativas de explicación por mecanismo (patrón no de ley pero causalmente informativo); también ha expul- 
sado la teleología de la explicación funcional e invertido el orden del aparato explicativo. De hecho, buena parte del atractivo de esta perspectiva naturalista radica en el hecho de haber fijado el papel azaroso de los cambios genéticos (mutación) dentro del proceso evolucionario y de haber reservado la función de criba y ordenamiento causal al mecanismo de la selección natural. Así ha podido ofrecer una mejor y más apropiada comprensión de la etiología evolucionaría y una pauta a seguir en otros campos propicios a la explicación por mecanismo. Frente a un reto tan potente, no parece razonable que la sociología pague en solitario el coste de evitar su participación en una tendencia que parece marcar de forma decisiva el rumbo de la ciencia contemporánea. «Parece urgente que los sociólogos aprendan a sentirse cómodos con la idea de un cierto determinismo genético [...] Si las ciencias siempre han compartido [sus mejores conquistas], ¿por qué no ha de hacerlo la sociología?» (ibídem).

\section{¿Sociobiología o sociobiologías?}

Muy tempranamente, al menos desde los años cuarenta, el término sociobiología empezó a usarse en etología y estudios del comportamiento animal para designar una ciencia interdisciplinaria que abrazaba la biología, la psicología y la sociología. Al margen de estos campos de investigación sistemática, una amplia producción de estudios divulgativos sobre la naturaleza humana ancestral se configuró a partir del concepto elemental de «instinto» (Lorenz, 1966; Ardrey, 1966) y precedió claramente a la síntesis sociobiológica oficial (Wilson, 1975). Pero, mientras esos trabajos gozaron de gran aceptación entre el amplio público, chocaron frontalmente contra una academia profundamente comprometida con paradigmas enaltecedores de la cultura y el relativismo cultural. Solo ello, y la inoportuna ocurrencia de E. O. Wilson de incluir la sociobiología como una rama nueva de la biología llamada a acometer el «estudio sistemático de las bases biológicas de todo comportamiento social», explica la feroz controversia desatada por el intento —en sí mismo razonable — de instaurar la concepción moderna del fundamento biológico de la cultura ${ }^{11}$. La animadversión se hizo particularmente notoria en el caso de los investigadores sociales y los antropólogos de la cultura. En su caso, no solo chocaba contra inercias teóricas heredadas; representaba además una amenaza a espacios disciplinarios institucionalmente blindados. Pero, muy a su pesar, el imparable avance de la biología y la genética en las décadas subsiguientes y, sobre todo, la relevancia científica, ética y social que alcanzó el Proyecto Genoma Humano a partir de los años ochenta, han hecho cada vez más plausible la idea de una única naturaleza humana e incrementado de forma sensible la receptividad de los argumentos biológicos. A este cambio de atmósfera ha contribuido también de forma decisiva la reciente fusión de la biología evolucionaría con la piscología cognitiva

11. Las acusaciones más feroces la quisieron vincular a formas modernas de darwinismo social o a políticas eugenésicas de raíz nazi, ambas malformaciones del pensamiento originario de Darwin, que, en conjunto, resultan esencialmente ajenas a los intereses de la sociobiología. 
en una nueva concepción de la explicación biológica del comportamiento humano: la psicología evolucionaria. Al poner un énfasis particular en la mente, la psicología evolucionaria de hoy resulta mucho más convincente, accesible y potable que la primera síntesis wilsoniana ${ }^{12}$, al tiempo que promete una base más sólida a la comprensión del comportamiento social y moral humano.

De todas formas, al hablar de sociobiología, conviene tener presente que se está haciendo referencia a un campo complejo cuyo desarrollo se ha hecho paulatinamente a partir de distintas contribuciones interdisciplinarias. Al tratarse de una idea seminal importante, la misma controversia ha servido para enriquecerla y perfilar cada vez mejor conceptos como «eficacia biológica inclusiva» (Hamilton, 1963, 1964), «selección por parentesco» (Maynard Smith, 1964), «altruismo recíproco» (Trivers, 1971) o «estrategias evolutivas estables» (Maynard Smith, 1972, 1982), etc., que han abierto grandes posibilidades e incorporado formalismos matemáticos que potencian enormemente las posibilidades del análisis evolucionario. Así, pues, de la primera síntesis sociobiológica de Wilson (1975) a la psicología evolucionaria contemporánea no hay un único término que sirva para designar con propiedad todos los intentos conocidos de aplicar la perspectiva naturalista darwiniana a la evolución del comportamiento humano. En este sentido, más que de «sociobiología» cabría hablar de «sociobiologías», de las que la idea estándar de Wilson es solo una de sus más polémicas acepciones. En la actualidad, se suele hablar de «ecología del comportamiento humano», "psicología darwinista» o "psicología evolucionaria». Jerome Barkow (2006: 5), uno de sus más señalados valedores, confiesa que él mismo ha cambiado de término a lo largo de los años. No obstante, la preferencia generalizada parece remitir a "psicología humana evolucionada» o "psicología evolucionaria» como la forma más adecuada de describir esta nueva perspectiva biológica de la mente humana que, sin pretensiones de convertirse en una nueva disciplina, se propone manifiestamente como una forma de "análisis conceptualmente integrado» de la biología evolucionaría con la psicología, y de la psicología con los fenómenos culturales (Barkow, Cosmides y Tooby, 1992).

\section{Genes y cultura}

La mayor resistencia con que tradicionalmente ha topado la sociobiología proviene de la arraigada concepción de la cultura humana como proceso único y esencialmente diferente de la evolución biológica. En efecto, la oposición de

12. Aunque Wilson (1998) continúa pensando que no se trata más que de una sociobiología de nueva generación, este énfasis en la mente humana ha hecho de la psicología evolucionaria una versión mucho más potable. La diferencia esencial entre ambas perspectivas radica en el hecho de que, mientras Wilson, incluso en sus nuevas versiones, siempre se ha ocupado de una evolución humana continua (el proceso seguido por gen, mente, cultura y sus bucles retroactivos), los psicólogos evolucionarios se centran en los rasgos de la arquitectura evolucionada de la mente, sin hacer particular mención a su evolución futura (Segersträle, 2000: 318). 
muchos investigadores sociales cultos a la idea de posibles restricciones biológicas al desarrollo de la cultura ha sido clásicamente argumentada desde la exclusiva capacidad humana de lenguaje. Eso explica por qué, incluso aquellos que, como Lévi-Strauss, no se han opuesto a esta perspectiva, se han cuidado de poner su límite en el comportamiento prelingüístico.

De todas formas, el espectro de reacciones a la perspectiva genética ha sido tan amplio que dentro del mismo pueden identificarse polos que van desde sus más declarados detractores (Marshall Sahlins la considera una simple intentona de lectura naturalista de la sociedad) ${ }^{13}$, hasta sus más decididos simpatizantes (como el grupo de investigadores de Irven DeVore, del que proceden Leda Cosmides y John Tooby, los padres de la actual psicología evolucionaria). En clave fundamentalista, pueden identificarse también antropólogos dispuestos a aplicar a la cultura humana los conceptos sociobiológicos de forma indiscriminada. El caso más saliente responde a las afirmaciones de la editora Laura Betzing, para quien «todo lo que pensamos, sentimos y hacemos debe pasar a ser mejor comprendido como medio para dispersar nuestros propios genes y los de nuestros ancestros» (1997: 2). Afortunadamente, la opinión prevalente es que ambos procesos, el genético y el cultural, son lo suficientemente complejos como para hacer prever interacciones igualmente intrincadas ${ }^{14}$.

Las sucesivas controversias en torno al fundamento biológico del comportamiento social humano han tenido el efecto lateral de promover un extenso debate sobre la coevolución de genes y cultura. Así, a lo largo de las tres últimas décadas, sus valedores, incluyendo el propio Wilson (Lumsden y Wilson, $1981)^{15}$, han tenido que responder a la presión de los críticos. De todas formas, resulta evidente que la relación entre genes y cultura no ha podido ser explorada a fondo hasta no tomar en cuenta la compleja naturaleza de la mente humana desde una perspectiva darwinista. De ahí lo interesante del reto intelectual asumido por la actual psicología evolucionaria y su empeño en desarrollar modelos que conecten explícitamente el desarrollo de la mente individual con la cultura y la cultura con la evolución biológica.

13. Dawkins (1979) se encargó de responder a lo que — también Maynard Smith (1984 en 1989: 192) — pasó a conocerse como «la falacia de Sahlins».

14. No extraña, así, encontrar, dentro de la misma compilación editada por Betzing, opiniones declaradamente contrarias: «Personalmente creemos que la cultura es necesaria [...] Sospechamos que lo que se ha querido decir es que podemos testar modelos de óptimos evolucionariamente inspirados sin hacer referencia a la cultura. Pero la cultura humana se interpone en la forma de maximizar la eficiencia biológica [...]. Una forma satisfactoria de comprender el comportamiento humano requiere examinar la articulación de rasgos previamente adaptativos con circunstancias culturales presentes» (Betzing, Krebs y Kacelnik, 1977: 28. Citado de Segersträle 2000 nota 15, p. 417).

15. En Lumsden y Wilson (1981: 2), las diferencias con la primera síntesis se hacen explícitas: «Al menos para el género humano, aquellos postulados eran radicalmente incorrectos. El comportamiento no está explícito en los genes y la mente no puede ser tratada como una mera réplica de rasgos de comportamiento. En este libro, proponemos una perspectiva muy diferente... [...] Ciertamente, los genes están vinculados a la cultura, pero lo están de una forma mucho más sutil y profunda». 


\section{Prevalencia analítica de las razones epistémicas}

En el otro extremo de las causas estructurales, y básicamente ajena al fundamento biológico de la conducta humana, una porción destacada de la teoría social del siglo XX ha puesto en el centro del análisis las acciones intencionales y las razones epistémicas relativas a creencias que atienden a cálculos racionales. De hecho, una buena parte de las variantes mentalistas del comportamiento individual y social en auge en las tres últimas décadas ha sido acometida desde modelos económicos de elección racional. Al margen del arraigo de su versión más colonizadora (la escuela de Chicago de Becker, 1976, y Coleman, 1990), decisiva en territorio europeo ha sido la influencia ejercida por el sociólogo francés Raymond Boudon (1979) y sus sucesivas aportaciones al Groupe d'Étude des Méthodes de l'Analyse Sociologique. Indiscutible también ha resultado la contribución de un puñado de marxistas analíticos, empeñados en divulgar la eficacia de las herramientas analíticas de la teoría de juegos a partir de sus redescripciones de temas marxistas. Particularmente sonada ha sido la influencia ejercida por el filósofo noruego Jon Elster (2007), quien, en sucesivos escritos, se ha ocupado de cuestiones de método y construcción de teorías de mecanismo intencional, argumentando contra cualquier pretensión de imperialismo económico, e ilustrado tanto la intención normativa de la teoría de la elección racional, como su restringida influencia explicativa o causal.

\subsection{Modelos económicos de racionalidad}

Dentro de estos modelos, la acción racional se considera básicamente como el resultado de un proceso mental guiado por alguna intención y orientado a un estado futuro de cosas. Se supone también que, de entre un conjunto de alternativas que el agente cree disponibles, la acción culmina siempre en la mejor elección. Y, en tanto esencialmente intencional e inaprehensible de forma directa, se prevé además la posibilidad de inferirla a partir de sus resultados entendidos en función de un criterio objetivo de óptimos que permite reconocer la acción como «racional».

Aunque el sentido intuitivo o primario de lo que se entiende por «racionalidad» asocia el término a una condición mínima de consistencia entre medios y fines, los desarrollos a los que aquí se hace referencia aluden más precisamente a la noción técnica heredada de la ciencia económica. Así, además de la condición básica de consistencia, la acepción económica atiende explícitamente a modelos de mercado en los que las creencias subjetivas se hacen coincidir con la realidad objetiva. Y, al suponer que los agentes económicos disponen de toda la información que necesitan (sobre los precios de equilibrio entre la oferta y la demanda), el modelo estándar de la racionalidad económica pasa a hacer referencia a creencias que se entienden fundadas en tanto normativamente válidas y causadas de forma correcta por la evidencia (razones epistémicas o razones fundadas para creer que). 
En general, se trata de una teoría que básicamente relaciona la acción con razones fundadas a partir de un patrón racional que discrimina ciertos subconjuntos de preferencias que cumplen con una lista de requisitos. Así, las supone completas (el decisor ha de ser capaz de comparar todas las alternativas); transitivas (si se prefiere $\mathrm{a}>\mathrm{b}$ y $\mathrm{b}>\mathrm{c}$, también se ha de preferir $\mathrm{a}>\mathrm{c}$ ); independientes (la maximización de la función de utilidad propia es indiferente a la curva de utilidad de los demás); han de satisfacer un principio de consistencia temporal (o a lo largo del tiempo), e implicar un problema de maximización de utilidad (han de maximizar bayesianamente consiguiendo la mayor utilidad al menor coste). Siempre que un agente exhiba ese patrón racional de preferencias, se podrán asignar números a sus alternativas de acción y, a partir de ahí, se podrán medir los valores relativos de utilidad que para él tienen dichas preferencias.

$\mathrm{Al}$ no tratarse de un dominio teóricamente unificado, resulta necesario diferenciar al menos dos tipos de modelos de racionalidad: el neoclásico o estándar de la «racionalidad paramétrica» y el de la "racionalidad estratégica» o teoría de la elección racional. Aunque en cada caso los patrones de preferencias racionales varían en matiz o grado respecto de las restricciones enunciadas, ambos modelos retienen la exigencia de razones epistémicas, puesto que en los dos las creencias se suponen racionales hasta el punto de ser causadas por la evidencia disponible y causadas además de forma correcta. Pero mientras, en la versión de los mercados enteramente competitivos se supone que los agentes económicos disponen de toda la información necesaria para decidir de forma maximizadora, la variante de la racionalidad estratégica introduce incertidumbre en el modelo que ha de incluir costes adicionales de adquisición de información. Al recoger la lógica de la decisión interdependiente se implica un supuesto de simetría racional y las matrices de juego remiten a sistemas interactivos en los que la decisión racional de Ego tiene que basarse en las expectativas - igualmente racionales- de Alter. Con ello no solo se contradice el supuesto del agente omnisciente; se fuerza también el principio estándar de independencia. No obstante, la ventaja comparativa de esta teoría es que resulta más adecuada para el análisis social, permitiendo identificar patrones recurrentes de preferencias estables que, una vez tipificados, ganan prestancia como posibles antecedentes de mecanismo intencional en explicaciones relativas a determinados contextos de interacción (Bowles, 2004).

Aún tratándose de una hipótesis de comportamiento plausible, el modelo de la elección racional no ha podido generalizarse y presentarse como una ley empírica importante que permita usarlo con intención genuinamente explicativa o causal. De hecho, los fallos de la teoría son numerosos. No solo falla porque la gente no siempre se comporta de forma racional, o porque por información deficiente también fracasa la racionalidad de las creencias. Falla además por falta de evidencia y, sobre todo, se malogra formalmente por la indeterminación de muchos juegos no cooperativos sin estrategia dominante que presentan más de una solución o no tienen resultado. Es evidente que todo 
ello ha contribuido a desmantelar cualquiera de sus tentaciones hegemónicas. Y, aun tratándose de una buena hipótesis de trabajo, también está claro que la tesis de la racionalidad estratégica apenas si tiene vigencia explicativa en relación con una cantidad limitada de aplicaciones.

\subsection{Pobreza antropológica del Homo economicus}

Limitados a la esfera del mercado, los modelos económicos se han visto generalmente comprometidos con un supuesto de hombre restringido a un conjunto de preferencias que les resulta formalmente manejable. De esta forma, han tendido a excluir sistemáticamente un amplio abanico de preferencias, normas y emociones o instintos sociales humanos (Elster, 2007). Ése, precisamente, parece haber sido el coste que ha tenido que pagar la ciencia económica para ganar excelencia formal: la reducción del agente económico a un paupérrimo conjunto de motivaciones.

En reiteradas ocasiones, destacados economistas han arremetido contra la miseria antropológica del Homo economicus y han criticado sus supuestos sobresimplificados o erróneos sobre la motivación humana (North, 1990: 17). Amartya Sen (1977: 328) llega a hablar de «idiotas racionales» para referirse a los agentes económicos que ignoran su capacidad recursiva y la posibilidad de preferencias de segundo orden. Para Herbert S. Simon (1987: 26-27), la noción de racionalidad económica se aleja sustancialmente de la de racionalidad psicológica: «Si el individuo racional de la economía neoclásica toma siempre la «mejor» decisión —objetiva y subjetivamente- en términos de una función de utilidad dada, la persona racional de la psicología cognitiva decide de forma solo procedimentalmente razonable y en función del conocimiento y de los medios de computación que tiene disponibles».

Hoy sabemos, además, que las capacidades evolutivamente seleccionadas para una mente limitada como la nuestra no nos permiten abrigar solo creencias y razonamientos bayesianamente correctos (las razones epistémicas de las que normativamente se ocupa el cálculo de probabilidad). Existen otras técnicas heurísticas no demostrativas igualmente eficientes y que funcionan como atajos instintivos capaces de ofrecer pautas alternativas de inferencia y juicios normativamente aproblemáticos (Gigerenzer, 2007). Así, al mismo tiempo que se cuestionan los modelos de base, en las últimas décadas se han ampliado sensiblemente las expectativas respecto de la posibilidad de razonamiento válido y objetivo.

\subsection{La racionalidad limitada}

Si bien la formación de creencias racionales requiere de información, la información misma no puede entrar en un análisis de costes-beneficios ya que solo puede evaluarse una vez que se posee. Esto hace suponer que los agentes económicos solo pueden maximizar sus funciones de utilidad si se conforman con el nivel de información de que disponen, o si pueden disponer de la informa- 
ción que necesitan sin coste añadido. Mientras la teoría neoclásica de los mercados de competición perfecta optó claramente por suponer que los agentes disponen de la información que necesitan para maximizar a coste cero, quienes no han suscrito este supuesto del agente omnisciente se han tenido que enfrentar a la difícil tarea de buscar criterios objetivos de satisfacción y proporcionar rutas alternativas a la racionalidad bayesiana.

Herbert S. Simon $(1957,1987)$ fue el primero en señalar explícitamente este defecto del modelo económico estándar y proponer una noción de racionalidad limitada, un cálculo racional «satisfaciente» (su satisficing theory) que hace suponer que los agentes indagan en el medio en busca de información y, una vez que han obtenido ciertos paquetes de datos sobre las alternativas disponibles (algo muy distinto a la asignación de probabilidades de utilidad a todas las consecuencias alternativas), toman aquella decisión que mejor satisface a sus expectativas dada esa información. Se trata, pues, de un comportamiento decisor limitado (bounded), en el que el agente se enfrenta a un mundo incierto y tiene que vérselas con información incompleta, obligado a buscar expresamente alternativas correctas de decisión.

Inicialmente mal acogida entre economistas, la noción de racionalidad satisfaciente o limitada acabó teniendo un gran impacto entre los investigadores sociales y, con el paso del tiempo, ha dado lugar a toda una familia de propuestas que tienden a alejarse de los modelos económicos para constituir el dominio específico de las «non utility oriented rationalities». En conjunto, todas esas propuestas comparten la intención de ofrecer una noción consensuada de racionalidad llamada a atender básicamente a condiciones de información imperfecta, capacidades computacionales limitadas y restricciones de tiempo en la toma de decisiones clave. Todas ellas suscriben postulados más realistas acerca del comportamiento elector humano y se proponen diseñar estrategias psicológicamente más plausibles y ecológicamente más eficientes. De esta forma, mientras la búsqueda de plausibilidad psicológica ha abierto un enorme horizonte en el que se invita a incursionar dentro de la mente humana (behavioral economics) ${ }^{16}$, la racionalidad ecológica explora fuera de ella para entender su interacción con la estructura del medio ${ }^{17}$. Ambas rutas de investigación continúan abiertas a interesantes pesquisas y desarrollos indepen-

16. La llamada "economía del comportamiento» (behavioral economics) parte de y entronca directamente con la psicología experimental, la ciencia cognitiva, recientes desarrollos de las ciencias de la computación, la inteligencia artificial y las neuroeconomics, modalidades todas que dan cauce al creciente interés en la condensación y sistematización de resultados de investigación empírica y experimental efectuados sobre ciertos postulados comportamentales y capacidades computacionales de la mente humana.

17. En este último terreno, la búsqueda ha proporcionado algunas claves interesantes relativas a las habilidades cognitivas de la mente humana, por lo general fundamentadas en la idea de que tales recursos o destrezas (en ambos sentidos, de potenciación, pero también de carencia) han sido perfiladas por la selección natural para la solución de problemas adaptativos planteados por los entornos específicos en los que evolucionó la especie (Gigerenzer y Selten, 2002). 
dientes, sin que nada haga presagiar que sus resultados sean mutuamente excluyentes o contradictorios (Samuels, Stich y Bishop, 2002).

\section{4. ¿Una matriz integradora para las ciencias del comportamiento?}

El cambio de clima académico propiciado a finales de los años ochenta por el trabajo interdisciplinario de las ciencias cognitivas y la biología evolucionaria ha hecho que la genética y la biología entren cada vez más en el mundo de la ciencia social. Y, al tiempo que su influencia va ganando terreno de forma progresiva, también se va debilitando la resistencia general a implicar ciertas restricciones biológicas en la explicación del comportamiento humano, comenzando a agotarse el predominio acrítico del paradigma culturalista. Así, la antropología social, por décadas interesada en evidenciar la tremenda diversidad de las culturas, ha acabado por centrar su análisis en los universales humanos, decantando definitivamente la vieja disputa entre culturalistas (tabula rasa) y universalistas (capacidades innatas), a favor de la perspectiva genética de las causas cognitivas.

A esta evidencia de que las ciencias biológicas y humanas o sociales están esencialmente interconectadas han contribuido también de forma directa los profundos cambios efectuados en el campo de la psicología. Así, de la psicología conductista de la selección por refuerzo a la psicolingüística de Chomsky y su subversiva idea de las competencias naturales o innatas, y de ésta a la revolución multidisciplinaria de las ciencias cognitivas y la tesis de la cognición humana como procesamiento de información, un nuevo hito ha sido marcado en las últimas décadas por la psicología evolucionaria al asociar la organización funcional del cerebro humano con el proceso biológico de la evolución. A partir de aquí, los fundamentos lógicos sobre los que se puede construir la arquitectura de la mente proporcionan información crítica acerca de rasgos característicos que aluden a mecanismos cognitivos evolucionariamente diseñados para resolver problemas adaptativos específicos. Con ello, la psicología cognitiva ha logrado liberarse no solo de los puntos ciegos de la intuición de la psicología común, sino también de la ceguera instintiva de la psicología conductista y del pesimismo del programa de heurísticas y sesgos de Kahneman y Tversky $(1982)^{18}$. Le ha permitido sobre todo diseñar experimentos cruciales para detectar mecanismos evolucionados antes impensables e inalcanzables.

Al facilitar la construcción de un marco conceptual único, todos estos cambios han alentado la integración de desarrollos interdisciplinarios hasta hace poco dispersos. Así, a pesar de su estadio preliminar, el conjunto de estos desarrollos parece muy prometedor. En efecto, con una cartografía - aunque incipiente - de la mente, no solo se pueden revisar retrospectivamente los plan-

18. La idea nuclear del programa de heurísticas y sesgos es que, en condiciones de incertidumbre, con frecuencia el juicio se basa en un número limitado y sobresimplificado de cálculos que no atienden a procesos lógicos o algoritmos extensivos, sino a heurísticas que, típicamente, dan juicios acertados aunque pueden involucrar también errores o sesgos sistemáticos. 
teamientos anteriores. Se puede también anticipar un nuevo horizonte, un paradigma alternativo que - prometedoramente - parece abrirse hoy ante las ciencias sociales y del comportamiento.

\section{Epílogo}

Revisados a la luz de las tres categorías propuestas ${ }^{19}$, los distintos intentos descritos a lo largo de este ejercicio representan respuestas parciales a viejas cuestiones que continúan esperando ser satisfactoriamente resueltas. A modo de recapitulación, se identificarán críticamente al menos los siguientes desaciertos entre las escuelas visitadas.

1. El primero de ellos es el de quienes, como las distintas modalidades del estructuralismo funcional, han atendido únicamente a las causas sociológicas. $\mathrm{Al}$ ignorar las causas cognitivas, el material genético queda reducido en sus versiones a unos cuantos impulsos o instintos primitivos, y la mente humana limitada solo a hacer posible la vida social y cultural sin contribuir de forma sustancial a su conformación (Barkow, Cosmides y Tooby, 1992: 29). Por otra parte, al ignorar los mecanismos psicológicos seleccionados para su adquisición, estos sociólogos ignoran también el indiscutible valor adaptativo de las razones epistémicas y su papel en la explicación de lo social.

2. En su desesperado intento por recuperar al sujeto humano, también la sociología subjetivista y el construccionismo sociológico de inspiración fenomenológica ha fallado al centrarse exclusivamente en las motivaciones del sujeto y posponer todas las causas estructurales (cognitivas y sociológicas). El problema en este caso es que, en ausencia de causas, todo acaba siendo - epistémica y ontológicamente- subjetivo. Además, al admitir una construcción social de la realidad por nosotros y para nuestros propósitos, se acaba vedando también la posibilidad de abrigar razones epistémicas. Y ello porque toda creencia racional supone la existencia de un mundo objetivo, aparte e independiente de cualquier razón subjetiva, acuerdo u opinión humana (Searle, 1995: 27-28).

3. Aunque con poca representación en la sociología, en tercer lugar se encuentran quienes solo se muestran dispuestos a admitir causas cognitivas. Tal es el caso de algunas versiones distorsionadas de la sociobiología que caen en el extremismo del determinismo genético (Betzing, 1997), negando toda función e impacto a la cultura. Es evidente que se trata de un defecto de bulto que el propio desarrollo del programa ha ido corrigiendo hasta llegar a versiones muy refinadas de la coevolución entre genes y cultura (Dawkins,

19. Así enunciada, debo la distinción entre causas sociológicas, causas cognitivas y razones epistémicas a la observación que hizo Domènech a propósito de mi reflexión (Lizón, 2000, n. 18: 78) sobre L'art de se persuader de Boudon (1990). Para una exposición filosófica más fina de causas estructurales y razones epistémicas, remitirse a Domènech (2005). 
1976; Lumsden y Wilson, 1981; Barkow, 1989; Boyd y Richerson, 1985). Solo cuando se ha incorporado adecuadamente la organización funcional del cerebro humano al proceso de evolución, se ha podido llegar a una versión científica y verdaderamente rompedora de psicología evolucionaria específicamente humana (Barkow, Cosmides y Tooby 1992).

4. En relación con aquellas teorías del intercambio entre mente y medio, que han sucumbido al mecanismo conductista y la selección por refuerzo, la implicación de supuestos inadecuados acerca de la naturaleza de la mente las ha hecho intrínsecamente problemáticas. De hecho, lo que Skinner pretendía con el esquema del estímulo-respuesta era eliminar cualquier estado mental del que emanaran acciones. El problema con ese planteamiento es que, mientras no se dispone de estadísticas históricas capaces de descifrar los estímulos a lo largo del tiempo, transcribirlos supone atender a causas cognitivas o principios relativos a la arquitectura de la mente. Carente de mecanismos evolucionados específicos para organizar los estímulos, el conductismo social ha tenido que asumir que los individuos desarrollan progresivamente sus estructuras cognitivas solo en respuesta a insumos externos. De este modo, su descripción psicológica pasa a depender de variables exógenas y falla al suponer la mente como desprovista de estructuras cognitivas o programas endógenos con contenido informativo, capaces de discriminar entre estímulos y de organizar las respuestas. Al asumir que, fundamentalmente, somos producto del medio, el conductismo social de teorías del intercambio como la de Homans se acerca problemáticamente al estructuralismo funcional que intenta criticar. De hecho, ambas escuelas conciben la mente como una suerte de reservorio vacío que espera ser llenado por diversos procesos sociales o moldeado por estímulos del entorno.

5. A pesar de que la versión alternativa del intercambio como comunicación supone variaciones importantes, también acarrea sus propios problemas. Para empezar, el programa del estructuralismo lingüístico parte del supuesto de un conjunto de reglas o gramáticas universales que funcionan de forma inconsciente. A la vez que con ello reafirma su diferencia fundamental respecto de la versión anterior, plantea también un problema adicional, ya que, en términos estrictos, las estructuras innatas no se observan de forma ni consciente ni inconsciente. De hecho, se trata de predisposiciones o capacidades básicas que, en conjunto, fijan el marco de posibilidad (inmediata o diferida) sobre el que se fundamentan los hechos mentales individuales y colectivos. Aluden así a capacidades reactivas previas a los estados mentales (creencias, deseos, etc.), que, a lo sumo, pueden tratarse como "preconscientes». Algo que también permite diferenciarlas de las causas sociológicas, que (consciente o inconscientemente) operan como restricciones ulteriores (o ex post), cribando el conjunto de oportunidad hasta disminuir o anular las posibilidades de acción autónoma. Y, además, permiten entender cómo el espacio reservado a la intencionalidad racional correlaciona con las causas cognitivas. 
6. Incluso estando bien dispuestos a admitir la distinción entre razones epistémicas y causas estructurales, muchos economistas han guardado silencio respecto de estas últimas. Ello se debe sobre todo a que el lenguaje económico suele confundir la racionalidad económica (los postulados que sirven para definirla formalmente) con lo que de hecho es la racionalidad. A propósito de esta concepción simplista, Cosmides y Tooby (1994: 327) tienen una deliciosa anécdota sobre aquel economista que, en un seminario interdisciplinario en el que se debatía sobre el comportamiento humano, saltó diciendo: «AAh! Ahora lo veo. Los datos o son racionales o son psicológicos». La formulación — comentan los articulistas después de rumiárselo — responde a un supuesto tácito, muy extendido entre estos especialistas, de que el comportamiento racional es una suerte de estado de naturaleza. Solo así se entiende que puedan aislar su discusión de correlatos relevantes, no solo de la sociedad y la política, sino también de la biología y la psicología evolucionaria $y$, en general, del resto de ciencias de la naturaleza. En abierto contraste, las ciencias cognitivas y la moderna psicología evolucionaria sostienen que los humanos nos comportamos en virtud de distintos mecanismos computacionales materializados en el tejido neuronal y seleccionados a lo largo de nuestro pasado evolutivo. Ello hace pensar que una explicación causal de cualquier comportamiento racional (o no) necesariamente tiene que invocar teorías acerca de esa compleja arquitectura de la mente y sus dispositivos motivacionales. Aunque los mantengan implícitos, parece claro que los modelos económicos presuponen teorías acerca de esos dispositivos computacionales. Y, lo admitan o no, también es evidente que hay claras conexiones analíticas y causales entre economistas, biólogos y psicólogos evolucionarios. La idea, justamente, es explicitarlas, ya que, de hacerlo, se podrían evitar muchas de las dificultades a las que se han venido enfrentando los modelos económicos de acción y elección racional.

7. Frente a las limitaciones y sesgos de la razón humana condensados en las distintas versiones de la racionalidad psicológica limitada (la bounded rationality), algunos han optado por vías de escape que acaban mezclando razones epistémicas, causas cognitivas y causas sociológicas. Así llegan a confundir «actuar conforme a la razón» con «actuar por buenas razones» (Boudon, 1990, 2003). Pero, aunque, efectivamente, toda razón es subjetiva, es evidente que se trata de cosas distintas. Mientras se entiende que la «razón» (en singular) obedece a cálculos objetivos, las «razones» (en plural) se toman como meras opiniones. Si bien no se trata de una distinción canónica (Elster, 2006: 14-15), es evidente que ambas cosas presentan diferencias respecto de su fuente normativa. Así, pues, se ha de evitar la equiparación indiscriminada de la razón epistémicamente fundada con aquellas razones subjetivamente fuertes que se distribuyen atendiendo a causas sociológicas. De hecho, en este último caso se trata de racionalizaciones o creencias subjetivas, opiniones más o menos verdaderas o dudosas que, aunque lleguen a distribuirse extensamente entre poblaciones, a lo sumo pueden contar analíticamente como razones «subjetivamente fuertes». 
8. Incluso admitiendo de forma explícita las causas cognitivas y estableciendo claramente lo que las diferencia de las causas sociológicas y de los cálculos estratégicos, propuestas tales como las de Bourdieu (1980) no acaban de dar cuenta de la relación causal entre esas disposiciones reactivas y los contenidos específicos de las reglas institucionales. En su alegato a favor de las capacidades colectivas de trasfondo, el filósofo analítico John Searle (1995: 154-55) propone invertir el orden del antecedente explicativo, intercambiando, a la manera de la explicación evolucionaria, dos niveles distintos de explicación. Así, en un primer nivel sincrónico o causal, se afirmaría que la capacidad o disposición adquirida («habitus») tiene la forma que tiene, porque la estructura reactiva («regularidad inmanente») hace posible que, en ese entorno ("potencialidad objetiva de la situación»), tenga esa forma específica. A partir de ahí, en un segundo plano funcional o diacrónico, se aseveraría que aquellos individuos en los que se ha activado esa habilidad preadaptada y causalmente responsiva al contenido de las reglas del campo, dispondrán de principios (schèmes) generadores que «harán posible la producción libre de todos los pensamientos, todas las percepciones y acciones inscritos dentro de los límites que marcan las condiciones particulares de su producción, y sólo éstas» (Bourdieu, 1980: 97). Ahora puede verse claramente cómo este tipo de explicación no implica una mera opinión generalizada, ni una simple internalización de reglas; tampoco responde a la consecución — consciente o inconsciente- de fines o cálculos estratégicos. En realidad, atiende a capacidades, habilidades o disposiciones reactivas que se activan colectivamente y hacen que las personas se comporten así porque es el modo que — de forma connatural — se conforma a las reglas institucionales del campo.

De entre las opciones mencionadas, muchas no han sido capaces de dar más que respuestas parciales y ninguna ha llegado a resolver satisfactoriamente la compleja relación entre causas estructurales y razones humanas. Es en este sentido que puede decirse que, más que de resolución teórica, el siglo XX ha sido un siglo de dispersión analítica. A pesar de tan mal diagnóstico de partida, el horizonte paradigmático al que se enfrentan las ciencias sociales a comienzos del nuevo milenio parece rico en posibilidades y caminos complementarios. Falta por ver si en esta ocasión la sociología se abre al reto interdisciplinario que le ofrecen la psicología evolucionaria y las modernas ciencias cognitivas. Es muy probable que su supervivencia teórica pase por hacerlo.

\section{Referencias bibliográficas}

ARDREY, R. (1966). The territorial imperative. Londres: Collins.

BARKOW, J. (ed.) (2006). Missing the revolution: Darwinism for social scientists. Nueva York: Oxford University Press.

- (1989). Darwin, Sex, and Status: Biological Approaches to Mind and Culture. Toronto: University of Toronto Press. 
BARKOW, J.; Cosmides, L. y ToOBY, J. (1992). The adapted mind: Evolutionary psychology and the generation of culture. Nueva York: Oxford University Press.

Bateson, P.P.G. (1982). «Preface». En: Kin’s College Sociobiology Group (ed). Current problems in sociobiology. Cambridge: Cambridge University Press.

BeCKer, G. (1976). Economic approach to human behavior. Chicago University Press. Berger, P. y LuCKMANn, T. (1966). La construcción social de la realidad. Buenos Aires: Amorrortu, 1968.

BetZING, L. (ed.) (1997). «Preface». En: Human nature. Oxford: Oxford University Press. Boudon, R. (1979a). La lógica de lo social. Madrid: Rialp, 1981.

- (1979b). "Generating models as a research strategy». En: MERTON, R. y ColEMAN, J. et al. (eds.) (1979). Qualitative and quantitative social research. Nueva York: The Free Press, 51-64.

- (1990). L'art de se persuader des idées douteuses, fragiles ou fausses. París: Fayard.

- (2003). Raison, bonnes raisons. París: P.U.F..

Bourdieu, P. (1980). El sentido práctico. Madrid: Taurus, 1991.

- (1984). La distinción: Criterios y bases sociales del gusto. Barcelona: Laia, 1991.

BOwLes, S. (2004). Microeconomics. behavior, institutions, and evolution. Princeton, N.J.: Princeton University Press, 3a reimpresión 2006.

BOYD, R. y RiCHERSON, P.J. (1985). Origin and evolution of culture. Oxford University Press.

Brown, D.E. (1991). Human universals. Nueva York, San Francisco: McGraw Hill. Caplan, A. (ed.) (1978). The sociobiological debate. Nueva York: Harper \& Row.

Chomsky, N. (1959). "A review of B. F. Skinner's "Verbal Behaviour"». Language, 35: 26-58. Traducción castellana: Proceso contra Skinner. Barcelona: Anagrama, 1975.

- (1965) Aspects of the Theory of Syntax. Cambridge: MIT Press.

- (1975). Logical structure of linguistic theory. Nueva York: Plenum Press.

Coleman, J. (1990). Foundations of social theory. Harvard University Press.

COSMIDES, L. (1989). "The logic of social exchange: Has natural selection shaped how humans reason?» Cognition, 31, 187-276.

- (1997). "The modular nature of human intelligence». En: SCHNEIBEL, A.B. y Schopf, J.W. (eds.). The Origin and Evolution of Intelligence. Boston: Jones \& Bartlett, 71-101.

Cosmides, L. y Tooby, J. (1992). «Cognitive adaptations for social exchange». En: BARKow, J.; Cosmides, L. y ToOBY, J. (1992), 163-228.

- (1994). "Better than rational: Evolutionary psychology and the invisible hand». American Economic Review, vol. 84(2), 327-332.

Cosmides, L.; TOOBY, J. y BARKOW, J. (1992). «Evolutionary psychology and conceptual integration». En: BARKOW, J.; Cosmides, L. y TOOBY, J. (1992), 3-15.

DAhrendorf, R. (1958). Homo sociologicus. Madrid: Akal, DL, 1975.

Dawkins, R. (1976). The Selfish Gene. Oxford University Press.

- (1979). «Twelve misunderstandings of kin selection». Zeitschrift für Tierpsychologie, 51: $184-200$.

Dennett, D. (1995). La peligrosa idea de Darwin. Barcelona: Galaxia Gutemberg, 2000.

DOMÈNECH, A. (2005). «El eterno retorno de Calicles. Sobre filosofía, relativismo y ciencia social». Enciclopedia Iberoamericana de Filosofía, vol. 28. Madrid: Trotta.

DURKHAM, W.H. (1978). "Toward a coevolutionary theory of human biology and culture». En: CAPLAN, A. (ed.) (1978). The sociobiological debate. Nueva York: Harper \& Row. 
EKeH, P.P. (1974). Social exchange theory: The two traditions. Cambridge: Harvard University Press.

Elio, R. (ed.) (2002). Common sense, reasoning and rationality. Vancouver Studies in Cognitive Science, vol. 11. Nueva York: Oxford University Press.

ElsTer, J. (2006). Raison et raisons. Collège de France: Fayard.

- (2007). Explaining social behavior: More nuts and bolts for the social sciences. Cambridge: Cambridge University Press.

FISKE, A. (1992). Structures of social life: The four elementary forms of human relations. Nueva York: The Free Press.

Fox, J. R. (1989). The Search for Society: Quest for a Biosocial Science and Morality. New Brunswick, New Jersey: Rutgers University Press.

Garfinkel, H. (1967). Studies in ethnomethodology. Englewood Cliffs, N. J.: PrenticeHall.

GigerenZER, G. (1997). "The modularity of social intelligence. En: WHITEN, A. y ByRne, R. (eds.). Machiavellian intelligence II. Cambridge: Cambridge University Press, 264-280.

- (2007). La inteligencia del inconsciente. Barcelona: Ariel, 2008.

Gigerenzer, G. y Murray, D.J. (1987). Cognition as intuitive statistics. Hillsdale, NJ: Lawrence Erlbaum Associates.

Gigerenzer, G. y Selten, R. (eds.) (2002). Bounded rationality: The adaptive toolbox. Cambridge: The MIT Press.

GiNTIS, H. (2009). The bounds of reason: Game theory and the unification of the behavioral sciences. Oxford: Princeton University Press.

Goffman, E. (1972). Strategic interaction. Nueva York: Ballantine.

GouldneR, A.W. (1970). La crisis de la sociología occidental. Buenos Aires: Amorrortu, 1973.

Hamilton, W.D. (1963). "The evolution of altruistic behavior». The American Naturalist, 97, 354-356.

Hirschfeld, L.A. y Gelman, S.A. (eds.) (1994). Mapping the mind: Domain specificity in cognition and culture. Nueva York: Cambridge University Press.

HogarTh, R. y Render, M. (eds.) (1987). Rational choice: Contrast between economics and psychology. Chicago: University of Chicago Press.

Homans, G.C. (1961). Social behavior: Its elementary forms. Nueva York: Harcourt Brace Jovanovich. Edición revisada.

- (1969). «The sociological relevance of behaviorism». En: BURGESS, R. y BUSHELL, D. (eds.). Behavioral sociology. Nueva York: Columbia University Press, 1-24.

KAHNEMAN, D. y TVERSKY, A. (1982). Judgement under uncertainty and heuristics biases. Cambridge: Cambridge University Press.

Kendall, P.; LaZARsfeld, P. (1950). «Problems of survey analysis». En: MerTON, R. y LaZArsfeld, P. (eds.). Continuities in Social Research. Studies in the Scope and Method of the American Soldier. Glencoe, Illinois: The Free Press, 133-196.

KREBS, J.; KACELNIK, A. (1997). "Yanomamo dreams and starling payloads: The logic of optimality». En: BETZING, L. (ed.). Human nature: A critical reader, 21-35.

LATOUR, B. (1979). Laboratory life: The construction of scientific facts. Princeton University Press.

LÉvi-STRAusss, C. (1949). Las estructuras elementales del parentesco. Barcelona: Paidós, 1988, 2a reimpresión.

- (1958). Antropología estructural. Barcelona: Paidós, 1987.

- (1964). Mitológicas. México: FCE, 1964 (4 vols.). 
Lizón, A. (2000). "Del "efecto Simmel” y la autopersuasión». Papers: Revista de Sociología. UAB, diciembre, 53-80.

LopreATO, J. (1999). Crisis in sociology. The need for Darwin. New Brunswick. Londres: Transaction Publishers.

LORENZ, K. (1966). On aggression. Londres: Methuen.

Lumsden, C.L. y Wilson, E.O. (1981). Genes, mind and culture: The coevolutionary process. Cambridge, MA y Londres: Harvard University Press.

MAYNARD SMITH, J. (1964). "Group selection and kin selection». Nature, 201, 11451147.

- (1982). Evolution and the Theory of Games. Cambridge: Cambridge University Press.

- (1984). Paleontology at the high table". Nature, reproducida en Maynard Smith 1989 Did Darwin Get it Right? Nueva York: Chapman and Hall, 125-30.

Merton, R.K. (1938). «Social structure and anomie». American Sociological Review, $3(5), 672-682$.

- (1949). Teoría y estructura sociales. México: Fondo de Cultura Económica, 1964.

Mills, W. (1959). La imaginación sociológica. México: Fondo de Cultura Económica, 1977.

Mundó, J. (2006). «Filosofía, ciencia social y cognición humana: De la Folk Psychology a la psicología evolucionaria». Papers: Revista de Sociología, 80, 257-281.

Natason, M. (1973). "Introduction". En A. Schütz, Collected Papers I: The Problem of Social Reality. La Haya: Martinus Nijhoff, xxv-xxxii.

Neuman, J. von y Morgenstern, O. (1947). Theory of games and economic behaviour. Princeton. N.J.: Princeton University Press.

NorTH, D. C. (1981). Structure and Change in Economic History. Nueva York: W.W. Norton \& Co.

- (1990). Instituciones, cambio institucional y desempeño económico. México, DF: Fondo de Cultura Económico, 1993.

PARSONS, T. (1937). La estructura de la acción social. Madrid: Guadarrama, 1968.

- (1951). El sistema social. $3^{a}$ ed. Madrid: Alianza, 1984.

Pinker, S. (1997). Cómo funciona la mente. Barcelona: Destino, 2000.

SaHlins, M. (1976). Use and abuse of biology. Ann Arbor: Michigan University Press.

SAMUELS, R.; STICH, S. y Bishop, M. (2002). "Ending of rationality wars: How to make disputes about human rationality disappear». En: ELIO, R. (ed.). Common sense, reasoning and rationality. Vancouver: Studies in Cognitive Science, vol. 11. N.Y.: Oxford University Press.

SCHER, S.J.; RAUSCHER, F. (eds.) (2002). Evolutionary psychology: Alternative approaches. Dordrecht: Kluwer Academic Publishers.

SchÜtz, A. (1932). La fenomenología del mundo social. Buenos Aires: Paidós, 1972. SEARLE, J. (1995). La construcción de la realidad social. Barcelona: Paidós, 1997.

Segersträle, U. (2000). Defenders of the Truth. The Sociobiology Debate. Oxford: Oxford University Press.

SEN, A.K. (1977). «Rational fools: a critique of the behavioural foundations of economic theory». Philosophy of Public Affairs, 6: 317-344.

Simon, H. (1957). Models of man: Social and rational. Mathematical essays on rational human behavior in a social setting. Nueva York: John Wiley \& Sons, Inc.

- (1987). "Rationality in psychology and economics». En: HOGARTH, R. y RENDER, M. (eds.) (1987). Rational choice: Contrast between economics and psychology. Chicago: University of Chicago Press, 25-40. 
- (1992). Economics, bounded rationality and the cognitive revolution. Aldershot Hants, England: Elgar.

SkinNER, B.F. (1957). Verbal behavior. Englewood Cliffs: Prentice Hall. México: Trillas, 1981.

- (1971). Más allá de la libertad y la dignidad. Barcelona: Editorial Fontanella 1973.

Sperber, D. (1968). «Le structuralisme en anthropologie». En: Ducrot et al. (eds.). Qu'est-ce que le structuralisme. Buenos Aires: Losada, 1971, 167-235.

ToObY, J. y COSMIDES, L. (1992). «The psychological foundations of culture». En: BARKOW J.H.; COSMIDES, L. y TOOBY, J. The adapted mind: Evolutionary psychology and the generation of culture. Nueva York: Oxford University Press, 19-136.

TRIVERS, R.L. (1971). "The evolution of reciprocal altruism». Quarterly Review of Biology, 46: 35-57.

Watson, J.B. (1930). Behaviorism. Chicago: Chicago University Press.

WeIngarT, P. et al. (eds.) (1997). Human by nature: Between biology and the social sciences. Mahwah, N.J.: Lawrence Erlbaum Associates, Publishers.

Whiten, A. y Byrne, R. (eds.) (1997). Machiavellian intelligence II. Cambridge: Cambridge University Press.

Wilson, E. O. (1975). Sociobiology: The New Synthesis. Cambridge, Mss: Harvard University Press.

— (1998). «Resuming the Enlightenment quest». The Wilson Quaterly, Winter, 16-27. 